\title{
Low-Cost Light-Weight Composite Metal Foams for Transportation Applications
}

\author{
Imre Norbert Orbulov, Attila Szlancsik, Alexandra Kemény, and Domonkos Kincses
}

\author{
Submitted: 29 October 2021 / Revised: 18 November 2021 / Accepted: 1 December 2021 / Published online: 23 February 2022
}

\begin{abstract}
This paper is dealing with the production and investigation (structural and mechanical) of composite metal foams (CMFs) with AISi9MgMn matrix and $\sim 60$ vol\% of different nominal diameter light expanded clay particles (LECPs) filler. The main aim was to produce a cheap CMF grade for automotive industry. The samples were produced by liquid state low pressure infiltration. Cubic samples were manufactured from the produced CMF blocks for structural (optical microscopy, scanning electron microscopy and energy-dispersive $x$-ray spectrometry (EDS)) and for mechanical (compression) investigations and tests. The CMFs were investigated in as-cast and in T6 heat-treated conditions. The macrostructural investigations showed homogenous structure and sufficient quality infiltration. On the microscopic scale, the EDS investigations revealed a complex interface layer affected by chemical reactions between the matrix material and the filler particles. The compressive test proved the classic foam-like mechanical behavior of the CMFs (with long plateau region). A relationship (valid for both the as-cast and T6 heat-treated conditions) was found between the characteristic properties and the nominal diameter of the filler. Based on these results, the LECPs filled CMFs are ideal candidates for automotive applications with tailorable properties.
\end{abstract}

Keywords automotive and transportation, composites, composite metal foam, mechanical testing, metallic matrix, porous materials

\section{Introduction}

Composite metal foams (CMFs) are metal matrix composites, made for density reduction in the base material and to gain unique material properties and features such as high energy absorption capacity and high specific strength values. Originally, CMFs were developed with Al alloy matrix and metallic hollow spheres (Ref 1-3). Later, the CMFs were further developed with steel matrix (Ref 4-7), and for defensive (armor) applications (Ref 8-10). Other matrix materials are also possible, and they are in the focus of the developments; for example, Mg (Ref 11-18), Ti (Ref 19-22), Zn (Ref 23-27) matrices are studied. One of the main challenges in the

This article is an invited submission to the Journal of Materials Engineering and Performance selected from presentations at the symposium "Advanced Materials for Transport Applications," belonging to the area "Energy" at the European Congress and Exhibition on Advanced Materials and Processes (EUROMAT 2021), held virtually from September $12-16,2021$, and has been expanded from the original presentation.

Imre Norbert Orbulov, Attila Szlancsik, Alexandra Kemény, and Domonkos Kincses, Department of Materials Science and Engineering, Faculty of Mechanical Engineering, Budapest University of Technology and Economics, Müegyetem rakpart 3, Budapest 1111, Hungary; and MTA-BME Lendület Composite Metal Foams Research Group, Müegyetem rakpart 3, Budapest 1111, Hungary. Contact e-mail: orbulov@eik.bme.hu. production of CMFs is their high cost, due to the price of the filler hollow spheres. Therefore, the cost reduction in CMFs is a logic and reasonable aim. For that purpose, different filler materials have been applied to produce CMFs, like expanded perlite (Ref 28-32), expanded glass (Ref 33-37) or expanded clay (Ref 38-42). Expanded perlite is polygonal; therefore, the structure is loaded by strong stress concentrators. Expanded glass is spherical, but mainly consisting of $\mathrm{SiO}_{2}$, that is strongly reactive with Al matrix. Light expanded clay particles (LECPs) are also spherical and consisting of mixed oxides, that provides some resistance against chemical reactions with properly selected Al alloy matrices. Szlancsik et al. (Ref 42) compared the properties of different size LECPs and found that they are promising candidates for CMF filler; therefore, this possibility is further mapped in the literature.

For example, Bonabi et al. (Ref 39) produced 73-78 vol\% porosity CMFs via casting with A355.0 matrix. The produced samples relative density was 0.44 , and their yield strength and energy absorption were measured to be $35.9 \mathrm{MPa}$ and 18.0 MJ.m ${ }^{-3}$, respectively. Puga et al. (Ref 41) applied AlSi7Mg matrix and LECPs with nominal diameter of 2.0, 3.5, 5.0 and $7.5 \mathrm{~mm}$ to produce CMFs by casting method. The samples made from the CMF blocks had the compressive strength of $32.2 \mathrm{MPa}$, densification deformation of 0.43 and energy absorption of $32.2 \mathrm{MJ}^{-3}{ }^{-3}$. Later, Kádár et al. (Ref 43) investigated the deformation and failure of LECPs filled A199.5 or AlSi12 matrix CMFs, produced by liquid state infiltration. The deformation mechanisms were monitored by acoustic emission recordings. A199.5 CMFs showed ductile behavior with long plateau, while AlSi12 matrix resulted in more brittle fracture. The acoustic emission analysis revealed that, the plastic deformation, and the fracture of the LECPs govern the failure mechanism of the CMFs. Szlancsik et al. (Ref 40) investigated AlSi10MnMg-based CMFs with LECPs fillers in as-cast and in T6 heat-treatment. The production method, the 
mechanical properties and the failure mechanisms were detailed in the paper.

More recently, LECPs filled tubes were also produced and investigated. Movahedi and Linul (Ref 44) applied $4 \mathrm{~mm}$ nominal diameter LECPs filled foam elements as the filler material inside empty thin-walled Al tubes. The compressive mechanical properties and the failure mechanisms were studied under quasi-static uniaxial compression. The foam filling resulted in $24 \%$ increment in the energy absorption and ensured more controlled failure modes with suppressed classic loss of mechanical stability of the tubes. Kemény et al. (Ref $45,46)$ modified the liquid state low pressure infiltration method to produce in situ CMFs filled Al tubes. In this technology, the infiltration of the LECPs happens in a thin-walled Al tube resulting in perfect bonding between the CMF and the tube to be filled (in classic ('ex-situ') cases the CMFs are produced separately, inserted into the tube, and fixed by gluing, soldering or by close fitting). AlSi12 alloy was applied as matrix, and AlMgSi0.5 tubes (inner diameter of $40 \mathrm{~mm}$ ) were filled by the CMFs produced with unimodal and bimodal LECPs (diameter ranges of 2.5-3.0 $\mathrm{mm}$ and 3.5-4 $\mathrm{mm}$ ). In situ filled tuber proved superior properties compared to ex situ filled tubes; moreover, the single step production is faster and cheaper.

The aim of this paper is to further investigate the LECPs filled CMFs, by mapping its mechanical properties and energy absorption capacity in the function of the diameter of LECPS and T6 heat-treatment.

\section{Materials and Methods}

In this section, the applied materials to produce the CMFs have been introduced along with the production and test methods.

\subsection{Materials}

As matrix material, AlSi9MgMn alloy as hardenable (precipitation hardening) aluminum alloy was applied. This grade is frequently used alloy in automotive industry and ideal for large series high pressure die casting. The AlSi9MgMn alloy CMFs were investigated in as-cast and in peak hardened (T6) conditions. The chemical composition of the matrix is listed in Table 1.

As filler materials light expanded clay particles (LECPs) were applied. The LECPs were provided by Liapor GmbH. \& Co. KG. (Hallerndorf-Pautzfeld, Germany). The chemical composition of the LECPs is $60 \pm 5 \mathrm{wt} \% \mathrm{SiO}_{2}, 17 \pm 3 \mathrm{wt} \%$ $\mathrm{Al}_{2} \mathrm{O}_{3}, 14 \pm 2 \mathrm{wt} \% \mathrm{Fe}_{2} \mathrm{O}_{3}$ and $\sim 9 \mathrm{wt} \%$ other oxides in sum, containing $\mathrm{CaO}, \mathrm{MgO}, \mathrm{Na}_{2} \mathrm{O}$, etc. The particle density of the LECPs was $0.75 \pm 0.05 \mathrm{~g} . \mathrm{cm}^{-3}$, while the loose bulk density of the particles was found to be $0.44 \pm 0.02 \mathrm{~g} . \mathrm{cm}^{-3}$. The particle density was calculated by measuring the weight and geometry of the individual particles (100 particles have been measured); then, the weight was divided by the calculated volume of the particles. The loose bulk density was measured by pouring a set of particles into a bin, and the overall weight of the particle set was divided by the overall occupied volume (including the space between the particles). The diameter of the LECPs was used as a research variable, and the available LECPs set was sieved into 3-5 $\mathrm{mm}, 7-9 \mathrm{~mm}$ and 10-11 mm subsets.
Table 1 Chemical composition of the matrix material (in wt\%)

\begin{tabular}{ccccccc}
\hline & Al & Si & Mg & Mn & Fe & Other \\
\hline AlSi9MgMn & 88.8 & 9.80 & 0.30 & 0.80 & 0.10 & 0.20 \\
\hline
\end{tabular}

\subsection{Production Methods}

CMF blocks were produced by low pressure liquid state infiltration, for details, please refer to (Ref 42). The blocks contained $\sim 60$ vol $\%$ LECPs. By the combination of the matrix materials, the heat-treatment conditions, and the nominal diameters of the LECPs nine types of CMF blocks were produced. From the blocks, cubic samples $(40 \times 40 \times 40(3-5$ $\mathrm{mm}$ LECPs filler) or $70 \times 70 \times 70 \mathrm{~mm}(7-9$ and $10-11 \mathrm{~mm}$ LECPs filler) in size) were machined, according to requirements of the ruling standard ISO13314:2011 (Ref 47). The samples were in as-cast (AC) or in T6 treated condition (the solution treatment was performed at $520^{\circ} \mathrm{C}$ for $1 \mathrm{~h}$, cooled in water and aged at $170^{\circ} \mathrm{C}$ for $10 \mathrm{~h}$ ). The samples were designated by the combination of the nominal LECPs diameter and the applied heat treatment (for example 8-T6 is for an AlSi9MgMn matrix CMF with 64 vol\% 7-9 mm LECPs filler aged for peak strength).

\subsection{Test Methods}

The samples were investigated microstructurally and mechanically. The microstructural investigations were done by optical microscopy (OM, Olympus PMG-3) and scanning electron microscopy (SEM, Zeiss EVO MA10), with attached energy-dispersive $\mathrm{x}$-ray spectrometry (EDS). For the microstructural investigations, the samples were carefully prepared, including grinding and polishing down to $1 \mu \mathrm{m}$ diamond finishing.

The mechanical tests were performed on a computer controlled MTS810 type $400 \mathrm{kN}$ hydraulic universal testing machine. The cubic samples were tested in a four-bar guided tool and lubricated by a thin PTFE foil to reduce friction between the sample and the tools. The velocity of the crosshead was $1 \mathrm{~mm} \cdot \mathrm{min}^{-1}$ (quasi-static compression), and the height reduction was measured by an extensometer (connected to the rigid loading plates). The compressive test run to 0.5 engineering deformation.

\section{Results and Discussion}

The most important physical property of metal foams is their density. The density of the samples was determined by the Archimedes method, and the densities were measured to be $1.45 \pm 0.020,1.51 \pm 0.017$ and $1.53 \pm 0.038{\mathrm{~g} . \mathrm{cm}^{-3}}^{-}$for $4 \mathrm{~mm}$, $8 \mathrm{~mm}$ and $11 \mathrm{~mm}$ filler, respectively. The corresponding relative densities are 54.5, 56.8 and $57.5 \%$. Further in this section, the results of the microstructural and mechanical measurements are introduced and discussed.

\subsection{Structural and Microstructural Investigations}

The structure of CMFs was observed on cross sections by optical microscopy, and a typical cross section is shown in Fig. 1. The distribution of the LECPs is even and homogenous, 


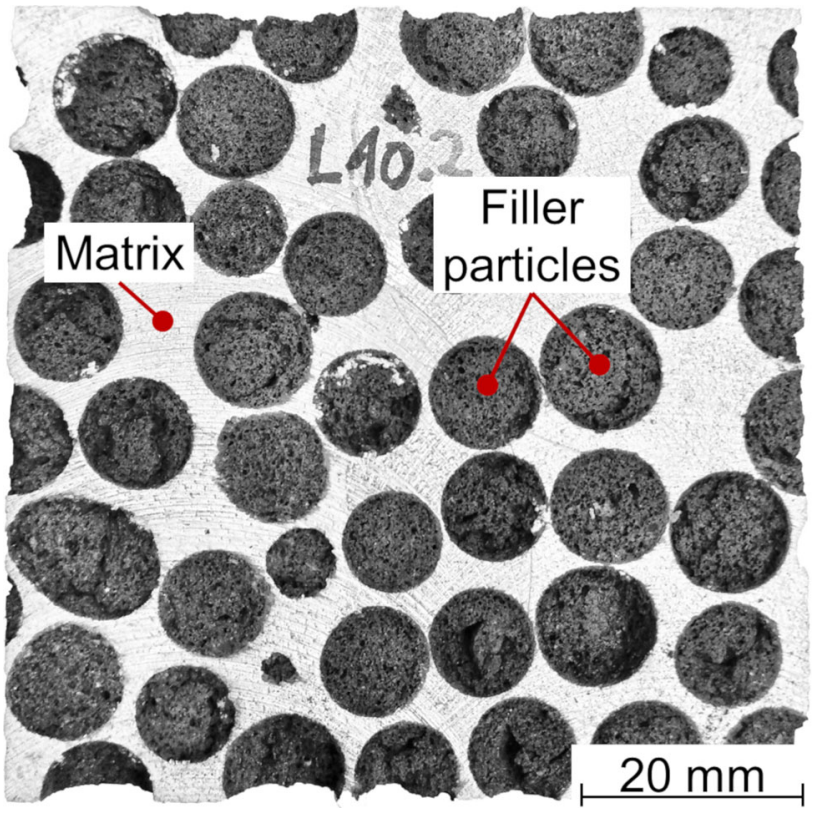

Fig. $1 \mathrm{OM}$ micrograph showing typical macrostructure of $10 \mathrm{~mm}$ average diameter LECPs filled AlSi9MgMn CMFs

and the cross sections of the LECPs are circular and regular in shape. Infiltrated LECPs cannot be observed, and the quality of infiltration is sufficient since there are no unfilled voids between the LECPs. The small metallic particles in the filler particles are originating from the cutting and polishing of the samples. The produced CMFs are sufficient in quality.

The microstructure of the LECPs filled CMFs was investigated by SEM in map data collection mode. The focus of the investigation was on the interfacial layer between the LECPs and the AlSi9MgMn matrix in order to gather information on the possible chemical reactions in this region. As a typical example, the interface of one single LECP is shown in Fig. 2(a). In the high magnification SEM micrograph, the matrix is shown on the left side, while the LECP is on the right side. In the matrix, precipitations can be observed, while the LECP's porous nature is also clearly shown. The matrix perfectly infiltrated the LECP pack, without voids between the matrix and the LECPs. On the border of the two phases, distinguished interface layer cannot be observed. Fig. 2(b) represents the composite EDS map of the same SEM scene pictured in Fig. 2(a). The precipitations in the matrix are Si-rich phase (Fig. 2c) embedded in the $\mathrm{Al}$ matrix (Fig. 2d). The presence of $\mathrm{Fe}$ is dominant in the LECPs (some Fe rich sites can be observed in Fig 2e), but as natural contaminant can be found in the Al matrix as well. K (Fig. 2f) and Ca (Fig. 2g) are identified in the LECP. The distribution of $\mathrm{K}$ is very smooth and even (Fig. 2f), and some enrichment can be found neat the interface layer, but mostly still in the LECP. Similarly, Ca can be found mainly in the LECP (Fig. 2g), but in coarser distribution, forming Ca-rich spots near to and in the interface layer. $\mathrm{Mg}$ (Fig. 2h) can be identified both in the matrix (smooth and evenly dispersed) and in the LECP (also evenly dispersed, but in higher concentration, due to the $\mathrm{MgO}$ content of the LECPs). The situation is the same for Mn (Fig. 2i), but the concentration is even in the matrix and in the LECP, with some enrichment in the matrix material parallel to the Fe-rich sites. The Na distribution (Fig. 2j) shows similar feature to the $\mathrm{Mg}$, but with less difference in the concentration between the matrix and LECP. $\mathrm{O}$ can be found in the LECP only, in detectable quantity (Fig. $2 \mathrm{k}$ ), because it is connected to the various oxides $\left(\mathrm{SiO}_{2}, \mathrm{Al}_{2} \mathrm{O}_{3}, \mathrm{Fe}_{2} \mathrm{O}_{3}, \mathrm{~K} 2 \mathrm{O}, \mathrm{CaO}, \mathrm{MgO}, \mathrm{MnO}_{2}\right.$, $\mathrm{Na}_{2} \mathrm{O}$ ). Last, the distribution of $\mathrm{P}$ (Fig. 21) is very similar to the distribution of $\mathrm{Na}$, with enrichments around the Fe rich spots (as one of the most important contaminant of Fe). In summary, the interface layer is invisible in SEM pictures, but can be found by the EDS. Fe, $\mathrm{K}$ and $\mathrm{Ca}$ enrichment in the matrix material near the outer surface of the LECPs is distinguishable due to the following chemical reactions between their oxides and the molten $\mathrm{Al}$ of the matrix (Eqs. 1-3).

$$
\begin{aligned}
& \mathrm{Fe}_{2} \mathrm{O}_{3}+2 \mathrm{Al} \rightarrow 2 \mathrm{Fe}+\mathrm{Al}_{2} \mathrm{O}_{3} \\
& 3 \mathrm{~K}_{2} \mathrm{O}+2 \mathrm{Al} \rightarrow 6 \mathrm{~K}+\mathrm{Al}_{2} \mathrm{O}_{3} \\
& 3 \mathrm{CaO}+2 \mathrm{Al} \rightarrow 3 \mathrm{Ca}+\mathrm{Al}_{2} \mathrm{O}_{3}
\end{aligned}
$$

These chemical reactions may have influence on the mechanical properties of the CMFs. Similar reactions would occur between $\mathrm{SiO}_{2}, \mathrm{MgO}$ and $\mathrm{MnO}$, but they are hindered by the significant $\mathrm{Si}, \mathrm{Mg}$ and $\mathrm{Mn}$ content of the matrix material.

In summary, the microstructural features of the investigated CMFs revealed good infiltration and complex interface layer between the particles and the matrix material.

\subsection{Mechanical Investigations}

The most important loading mode of CMFs is compression, and the only standardized test method of metal foams is the compressive test (Ref 47). The compressive tests were performed on cubic samples, and the calculated compressive stress versus compressive deformation curves are plotted in Fig. 3, for better comparison, the scales in the subfigures are identical. In the plots, the engineering system was used.

The CMFs can be qualified by their characteristic strength and energy absorption values. The most important strength values are the yield strength (the strength value at a distinguished remaining ('plastic') engineering deformation value, typically at 0.01 -analog to the $0.2 \%$ proof strength in the case of classic tensile tests) and the plateau stress level (the average stress level between two distinguished engineering deformation limits, typically between 0.1 and 0.4 (Ref 47)). The yield strength shows the onset of the large-scale deformation, therefore important in the design process for structural applications, where the deformation should remain elastic only. On the other hand, the plateau strength and the overall energy absorption also characterize the CMFS. The plateau strength shows the stress level of the energy absorption during the irreversible deformation of the CMFs and crucial in the applications aiming effective energy absorption (collision dampers, crash boxes, etc.). The energy absorption shows the overall capacity of the CMFs to absorb mechanical energy and equals to the area below the stress-strain curve up to a given deformation level ( 0.5 engineering deformation in our case).

The effects of the LECPs' nominal diameter and the heat treatment are evident from Fig. 3. The lowest strength values are provided by the largest LECP fillers both in AC and in T6 condition. Qualitatively, by decreasing the nominal diameter, the strength values as well as the absorbed mechanical energy increased. The T6 heat-treatment almost doubled the yield strength and the plateau stress level as well. The same can be 

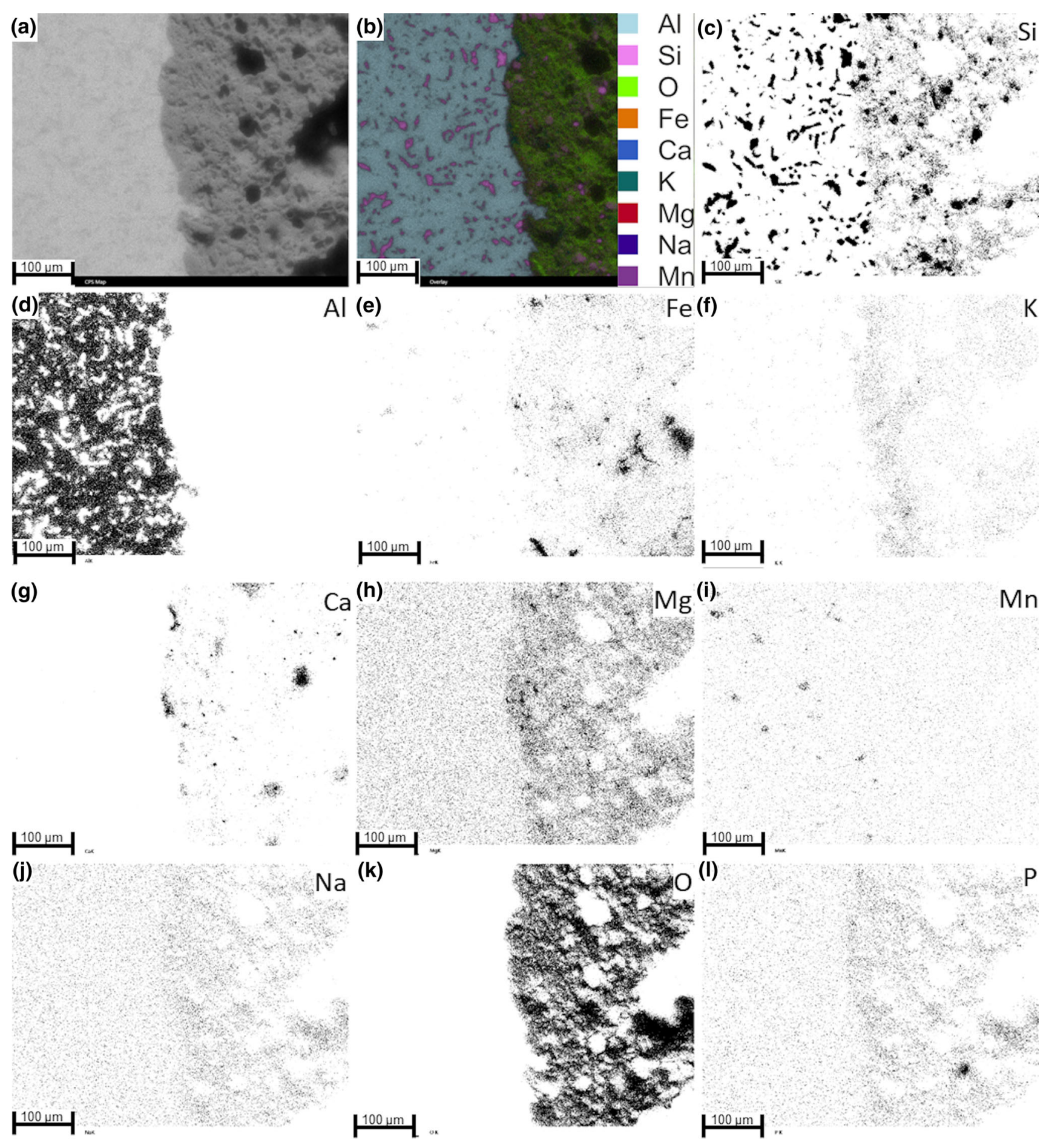

Fig. 2 SEM picture (a), composite EDS map (b) and the distribution of each investigated elements (c-1)

concluded for the energy absorption, too. The initial linear elastic part of the compressive curves becomes higher and higher by decreasing the nominal diameter of the filler. In accordance with the correspondingly increasing strength values, the onset of the large-scale deformation occurs earlier, and the CMFs show more brittle behavior.

The effects of the diameter and the heat treatment on the characterizing properties can be plotted in individual graphs (one for the strength properties and another for the absorbed energy), visualized in Fig. 4.
In the case of the investigated strength and absorbed energy values, an analytical relationship (Eq 4) was found that can be used to predict the properties ( $\mathrm{P}$ in general) of the CMFs based on the nominal diameter (D) of the LECPs filler.

$\mathrm{P}=\mathrm{A}+\mathrm{Be}^{-\mathrm{CD}}$

where $\mathrm{P}$ is the property in question, $\mathrm{D}$ is the nominal diameter of the LECPs, while A, B and C are fitting parameters. A is the asymptote of the decay function of $\mathrm{Eq} 4, \mathrm{~B}$ is the magnitude 

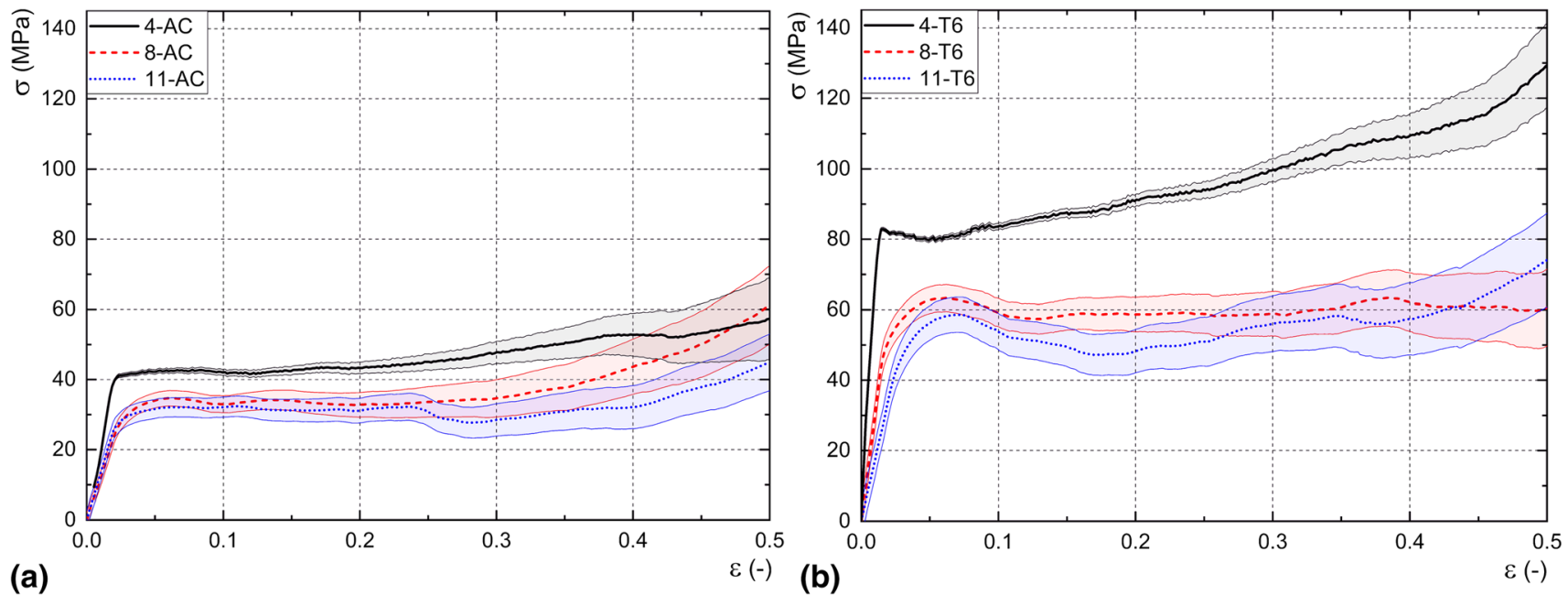

Fig. 3 Compressive stress versus compressive deformation curves of the CMFs in as-cast (a) and in T6 (b) condition
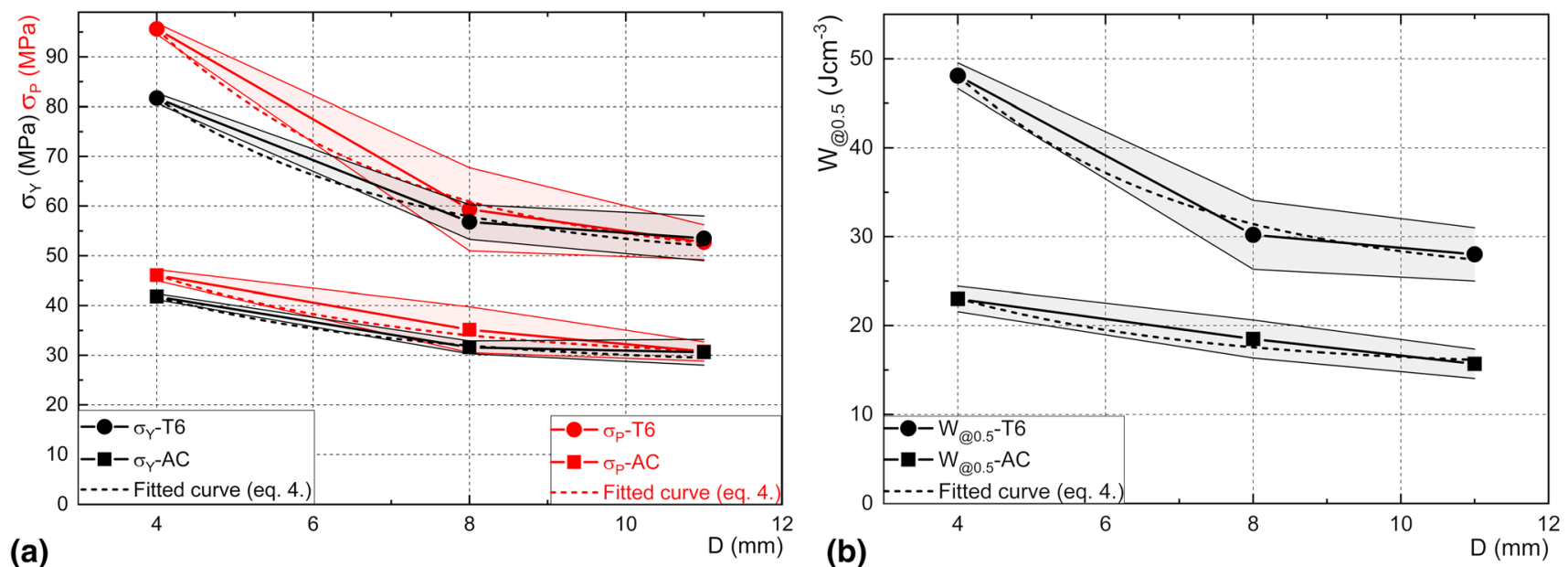

Fig. 4 The strength properties (a) and the absorbed energy values (b) as the function of the LECPs nominal diameter

and exponent, and $\mathrm{C}$ is the rate of the decrement in the property by the increment of the diameter.

The results of Table 2 show a $\sim 0.3$ decay exponent for Eq 4 with a quite narrow scatter band, confirming the identical effect of the LECPs diameter on the most important strength and energy absorption properties. This fact makes LECPs filled CMFs ideal candidates for energy absorbers with tailorable energy absorption capacity and stress level.

The absorbed energy values at a single maximal compressive deformation $(\varepsilon=0.5)$ provide limited details about the energy absorption characteristics of the CMFs, therefore as additional information, the energy absorption curves are plotted in Fig. 5.

The energy absorption is almost a linear function of the compressive deformation. Originating from the compressive curves, the smallest filler particles ensured the highest energy absorption at any deformation. In the initial $(\varepsilon<0.1)$ and in the plateau region (shaded area in Fig. 5, $0.1 \varepsilon<<0.4$ ), the energy absorption was linear. After the plateau region, some positive deviation from the linear relationship can be seen as the densification begun. T6 heat-treated samples can absorb significantly higher energy due to their higher plateau stress
Table 2 Fitting parameters for Eq. 4

\begin{tabular}{lccrcc}
\hline Property & Condition & $\mathbf{A}$ & $\mathbf{B}$ & $\mathbf{C}$ & $\mathbf{R}^{\mathbf{2}}$ \\
\hline$\sigma_{\mathrm{Y}}$ & $\mathrm{AC}$ & 27.85 & 47.39 & 0.3060 & 0.996 \\
& $\mathrm{~T} 6$ & 48.13 & 115.01 & 0.3080 & 0.997 \\
$\sigma_{\mathrm{P}}$ & $\mathrm{AC}$ & 28.81 & 57.47 & 0.3003 & 0.999 \\
& $\mathrm{~T} 6$ & 47.10 & 170.04 & 0.3134 & 0.999 \\
$\mathrm{~W}_{@ 0.5}$ & $\mathrm{AC}$ & 15.17 & 26.21 & 0.2993 & 0.977 \\
& $\mathrm{~T} 6$ & 24.89 & 82.28 & 0.3168 & 0.997 \\
Average & & & & 0.3073 & \\
\multicolumn{2}{l}{ Standard deviation } & & & 0.0069 & \\
\hline
\end{tabular}

level (resulting in higher reaction forces, on the other hand). The energy absorption curves are useful for the design of energy absorbing parts and elements.

During the compression tests, the CMF samples showed a typical failure mode as it is presented in Fig. 5 for an AlSi9MgMn matrix, $10 \mathrm{~mm}$ LECPs filled CMF at 0.5 compressive engineering deformation. As it can be seen in the figure, the cell struts between the LECPs particles were 

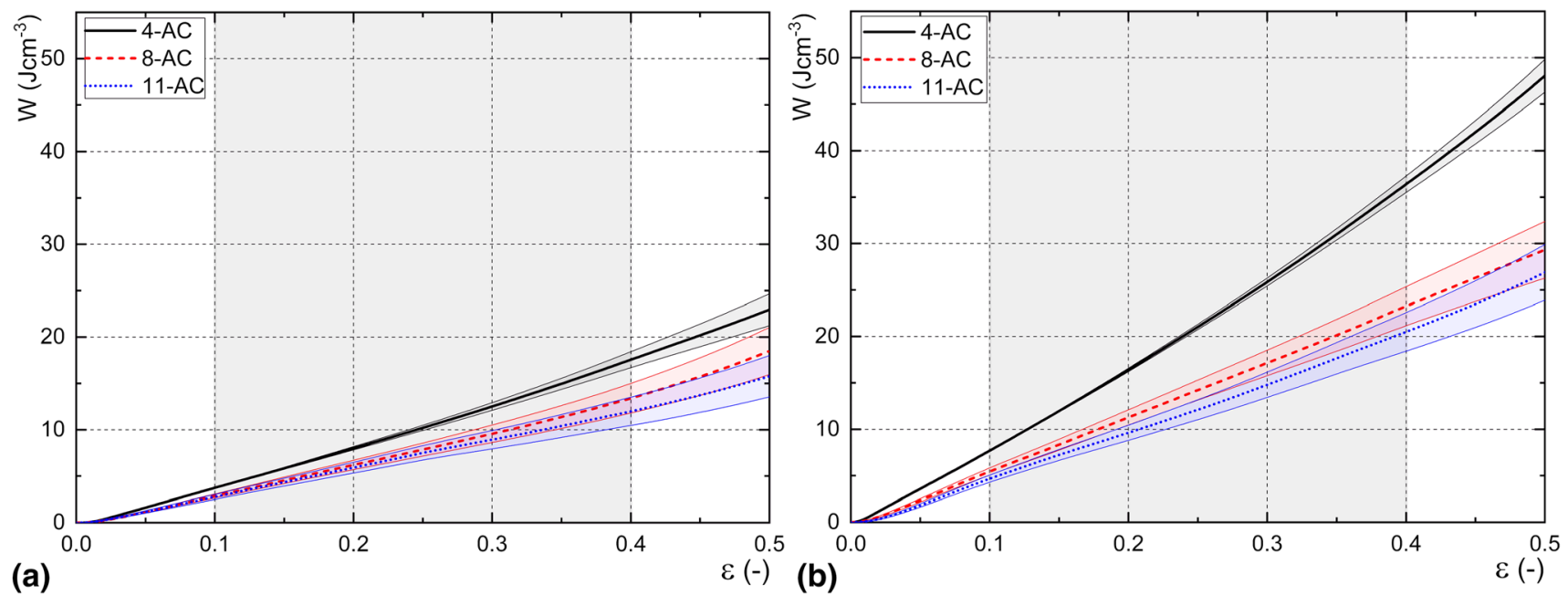

Fig. 5 Absorbed energy versus compressive deformation curves of the CMFs in as-cast (a) and in T6 (b) condition

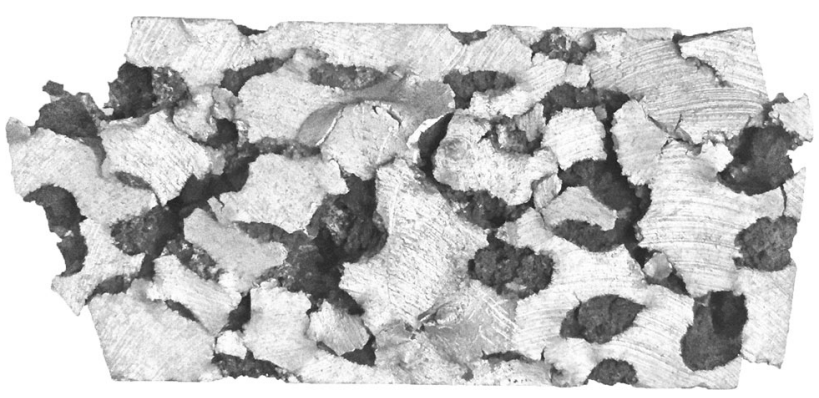

Fig. 6 OM macrograph showing typical failure of $10 \mathrm{~mm}$ average diameter LECPs filled AlSi9MgMn CMFs at 0.5 compressive engineering deformation

deformed and broken and the LECPs were collapsed due to the vertical compressive load. No distinguished shear band(s) can be highlighted in the sample, and the failure was continuous and uniform. The sample remained intact even at the highest compressive deformation (Fig. 6).

\section{Conclusions}

Low-cost, light-weight LECPs filled AlSi9MgMn matrix CMFs with $\sim 60 \mathrm{vol} \%$ filler content were produced and investigated (structural and compressive investigations). From the experiments and results detailed in the paper, the following conclusions can be drawn.

- Low pressure infiltration is a proper method to incorporate cheap, low density LECPs into the AlSi9MgMn matrix material, well-known and widely used in automotive industry.

- The structure of the produced CMFs was homogenous, the interface layer between the LECPs and the matrix material proved to be strong due to the chemical reactions between the constituents.

- The investigated characteristic properties (yield strength, plateau stress level and absorbed mechanical energy) were influenced by the nominal diameter of the filler and by the applied heat treatment.

- Mathematical relationship between the nominal diameter and the investigated properties were found in as-cast and in $\mathrm{T} 6$ treated conditions, too.

- The decay exponent in the relationship was found to be $0.3073 \pm 0.0069$ and valid for all the investigated characteristic properties, meaning identical effect of the nominal diameter on all the investigated properties. This fact makes LECPs filled CMFs ideal candidates for automotive applications with tailorable properties.

\section{Acknowledgment}

The research reported in this paper and carried out at BME has been supported by the NRDI Fund (TKP2020 IES, Grant No. BME-IE-NAT) based on the charter of bolster issued by the NRDI Office under the auspices of the Ministry for Innovation and Technology. The research reported in this paper and carried out at BME has been supported by the NRDI Fund (TKP2020 NC, Grant No. BME-NC) based on the charter of bolster issued by the NRDI Office under the auspices of the Ministry for Innovation and Technology.

\section{Funding}

Open access funding provided by Budapest University of Technology and Economics.

\section{Open Access}

This article is licensed under a Creative Commons Attribution 4.0 International License, which permits use, sharing, adaptation, distribution and reproduction in any medium or format, as long as you give appropriate credit to the original author(s) and the source, provide a link to the Creative Commons licence, and indicate if changes were made. The images or other third party material in this article are included in the article's Creative Commons licence, unless indicated otherwise in a credit line to the material. If material is not included in the article's Creative Commons licence 
and your intended use is not permitted by statutory regulation or exceeds the permitted use, you will need to obtain permission directly from the copyright holder. To view a copy of this licence, visit http://creativecommons.org/licenses/by/4.0/.

\section{References}

1. A. Rabiei and A.T. O'Neill, A Study on Processing of a Composite Metal Foam via Casting, Mater. Sci. Eng. A, 2005, 404, p 159-164. h ttps://doi.org/10.1016/j.msea.2005.05.089

2. L.J. Vendra and A. Rabiei, A Study on Aluminum-Steel Composite Metal Foam Processed by Casting, Mater. Sci. Eng. A, 2007, 465(1), p 59-67. https://doi.org/10.1016/j.msea.2007.04.037

3. A. Rabiei and L.J. Vendra, A Comparison of Composite Metal Foam's Properties and Other Comparable Metal Foams, Mater. Lett., 2009 h ttps://doi.org/10.1016/j.matlet.2008.11.002

4. B.P. Neville and A. Rabiei, Composite Metal Foams Processed through Powder Metallurgy, Mater. Des., 2008, 29(2), p 388-396. https://doi. org/10.1016/j.matdes.2007.01.026

5. L.J. Vendra, B. Neville and A. Rabiei, Fatigue in Aluminum-Steel and Steel-Steel Composite Foams, Mater. Sci. Eng. A, 2009, 517(1), p 146 153. https://doi.org/10.1016/j.msea.2009.03.075

6. A. Rabiei and M. Garcia-Avila, Effect of Various Parameters on Properties of Composite Steel Foams Under Variety of Loading Rates, Mater. Sci. Eng. A, 2013, 564, p 539-547. https://doi.org/10.1016/j. msea.2012.11.108

7. A. Rabiei, K. Karimpour, D. Basu and M. Janssens, Steel-Steel Composite Metal Foam in Simulated Pool Fire Testing, Int. J. Therm. Sci., 2020, 153, p 106336. https://doi.org/10.1016/J.IJTHERMALSCI. 2020.106336

8. A. Rabiei, M. Portanova, J. Marx, C. Scott and J. Schwant, A Study on Puncture Resistance of Composite Metal Foam Core Sandwich Panels, Adv. Eng. Mater, 2020 https://doi.org/10.1002/adem.202000693

9. J. Marx, M. Portanova and A. Rabiei, Performance of Composite Metal Foam Armors against Various Threat Sizes, J. Compos. Sci., 2020, 4(4), p 176. https://doi.org/10.3390/jcs4040176

10. J. Marx, M. Portanova and A. Rabiei, Ballistic Performance of Composite Metal Foam against Large Caliber Threats, Compos. Struct., 2019, 225, p 111032. https://doi.org/10.1016/J.COMPSTRUCT.2019. 111032

11. P. Kubelka, C. Kádár and N. Jost, Effect of the Interface on the Compressive Properties of Magnesium Syntactic Foams, Mater. Lett., $2021 \mathrm{https}: / /$ doi.org/10.1016/j.matlet.2020.129293

12. S. Kannan, S. Pervaiz, R. Klassen, D. Huo and M. Haghshenas, An Energy-Based Analysis for Machining Novel AZ91 Magnesium Composite Foam Dispersed with Ceramic Microspheres, J. Manuf. Sci. Eng., 2020 https://doi.org/10.1115/1.4048438

13. K. Samvatsar and H. Dave, A Comprehensive Study on Using Fly Ash as Reinforcement Material in Aluminium and Magnesium Based Syntactic Foams, Mater. Today Proc., 2021 https://doi.org/10.1016/j. matpr.2021.04.353

14. X. Xia, J. Feng, J. Ding, K. Song, X. Chen, W. Zhao, B. Liao and B. Hur, Fabrication and Characterization of Closed-Cell MagnesiumBased Composite Foams, Mater. Des., 2015, 74, p 36-43. https://doi. org/10.1016/j.matdes.2015.02.029

15. G. Anbuchezhiyan, B. Mohan, D. Sathianarayanan and T. Muthuramalingam, Synthesis and Characterization of Hollow Glass Microspheres Reinforced Magnesium Alloy Matrix Syntactic Foam, J. Alloys Compd., 2017, 719, p 125-132. https://doi.org/10.1016/j.jallcom.2017. 05.153

16. A. Padnuru Sripathy, C. Handjaja, V. Manakari, G. Parande and M. Gupta, Development of Lightweight Magnesium/Glass Micro Balloon Syntactic Foams Using Microwave Approach with Superior Thermal and Mechanical Properties, Metals, 2021, 11, p 827.

17. H. Anantharaman, V.C. Shunmugasamy, O.M. Strbik, N. Gupta and K. Cho, Dynamic Properties of Silicon Carbide Hollow Particle Filled Magnesium Alloy (AZ91D) Matrix Syntactic Foams, Int. J. Impact Eng., 2015, 82, p 14-24. https://doi.org/10.1016/j.ijimpeng.2015.04. 008

18. K.N. Braszczyńska-Malik, Types of Component Interfaces in Metal Matrix Composites on the Example of Magnesium Matrix Composites, Materials, 2021, 14, p 5182.
19. D.P. Mandal, D.D. Majumdar, R.K. Bharti and J.D. Majumdar, Microstructural Characterisation and Property Evaluation of Titanium Cenosphere Syntactic Foam Developed by Powder Metallurgy Route, Powder Metall., 2015, 58(4), p 289-299. https://doi.org/10.1179/174 3290115Y.0000000012

20. N. Jha, D.P. Mondal, M.D. Goel, J.D. Majumdar, S. Das and O.P. Modi, Titanium Cenosphere Syntactic Foam with Coarser Cenosphere Fabricated by Powder Metallurgy at Lower Compaction Load, Trans. Nonferrous Met. Soc. China, 2014, 24(1), p 89-99. https://doi.org/10. 1016/S1003-6326(14)63032-6

21. D.P. Mondal, J. Datta Majumder, N. Jha, A. Badkul, S. Das, A. Patel and G. Gupta, Titanium-Cenosphere Syntactic Foam Made Through Powder Metallurgy Route, Mater. Des., 2012, 34, p 82-89. https://doi. org/10.1016/j.matdes.2011.07.055

22. X. Xue and Y. Zhao, Ti Matrix Syntactic Foam Fabricated by Powder Metallurgy: Particle Breakage and Elastic Modulus, JOM, 2011, 63(2), p 43-47. https://doi.org/10.1007/s11837-011-0027-0

23. S. Broxtermann, M. Vesenjak, L. Krstulović-Opara and T. Fiedler, Quasi Static and Dynamic Compression of Zinc Syntactic Foams, $J$. Alloys Compd., 2018, 768, p 962-969. https://doi.org/10.1016/J.JAL LCOM.2018.07.215

24. E. Linul, D. Lell, N. Movahedi, C. Codrean and T. Fiedler, Compressive Properties of Zinc Syntactic Foams at Elevated Temperatures, Compos. Part B Eng., 2018, 167, p 122-134. https://doi.org/10. 1016/J.COMPOSITESB.2018.12.019

25. N. Movahedi, E.G. Murch, V.I. Belova and T. Fiedler, Effect of Heat Treatment on the Compressive Behavior of Zinc Alloy ZA27 Syntactic Foam, Materials, 2019, 12, p 792.

26. K. Al-Sahlani, E. Kisi and T. Fiedler, Impact of Particle Strength and Matrix Ductility on the Deformation Mechanism of Metallic Syntactic Foam, J. Alloys Compd., 2019 https://doi.org/10.1016/J.JALLCOM. 2019.01.283

27. T. Fiedler, K. Al-Sahlani, P.A. Linul and E. Linul, Mechanical Properties of A356 and ZA27 Metallic Syntactic Foams at Cryogenic Temperature, J. Alloys Compd., 2020, 813, p 152181. https://doi.org/ 10.1016/J.JALLCOM.2019.152181

28. M. Taherishargh, M.A. Sulong, I.V. Belova, G.E. Murch and T. Fiedler, On the Particle Size Effect in Expanded Perlite Aluminium Syntactic Foam, Mater. Des., 2015, 66, p 294-303. https://doi.org/10.1016/j.ma tdes.2014.10.073

29. M. Taherishargh, I.V. Belova, G.E. Murch and T. Fiedler, The Effect of Particle Shape on Mechanical Properties of Perlite/Metal Syntactic Foam, J. Alloys Compd., 2017, 693, p 55-60. https://doi.org/10.1016/j. jallcom.2016.09.168

30. M. Taherishargh, I.V. Belova, G.E. Murch and T. Fiedler, Low-Density Expanded Perlite-Aluminium Syntactic Foam, Mater. Sci. Eng. A, 2014, 604, p 127-134. https://doi.org/10.1016/j.msea.2014.03.003

31. M. Taherishargh, I.V. Belova, G.E. Murch and T. Fiedler, On the Mechanical Properties of Heat-Treated Expanded Perlite-Aluminium Syntactic Foam, Mater. Des., 2014, 63, p 375-383. https://doi.org/10. 1016/j.matdes.2014.06.019

32. M. Taherishargh, E. Linul, S. Broxtermann and T. Fiedler, The Mechanical Properties of Expanded Perlite-Aluminium Syntactic Foam at Elevated Temperatures, J. Alloys Compd., 2018, 737, p 590-596. h ttps://doi.org/10.1016/J.JALLCOM.2017.12.083

33. C. Bolat and A. Goksenli (2020) Fabrication Optimization of Al 7075/ Expanded Glass Syntactic Foam by Cold Chamber Die Casting, Arch. Foundry Eng., The Katowice Branch of the Polish Academy of Sciences, 20(3), 112-118

34. M. Su, H. Wang, H. Hao and T. Fiedler, Compressive Properties of Expanded Glass and Alumina Hollow Spheres Hybrid Reinforced Aluminum Matrix Syntactic Foams, J. Alloys Compd., 2019, 821, p 153233. https://doi.org/10.1016/J.JALLCOM.2019.153233

35. S. Broxtermann, M.M. Su, H. Hao and T. Fiedler, Comparative Study of Stir Casting and Infiltration Casting of Expanded Glass-Aluminium Syntactic Foams, J. Alloys Compd., 2020 https://doi.org/10.1016/j.jallc om. 2020.155415

36. K. Al-Sahlani, M. Taherishargh, E. Kisi and T. Fiedler, Controlled Shrinkage of Expanded Glass Particles in Metal Syntactic Foams, Materials, 2017, 10, p 1073.

37. A. Wright and A. Kennedy, The Processing and Properties of Syntactic Al Foams Containing Low Cost Expanded Glass Particles, Adv. Eng. Mater., 2017, 19(11), p 1-6. 
38. C. Wiener, K. Máthis, F. Chmelík, M. Knapek, and I.N. Orbulov, The Deformation of Expanded Clay Syntactic Foams During Compression Characterized by Acoustic Emission, Proceedings of the 11th International Conference on Porous Metals and Metallic Foams (MetFoam 2019), N. Dukhan, Ed., (Dearborn (MI)), Springer International Publishing, 2020, p 107-114 PG-8, doi:https://doi.org/10.1007/978-3030-42798-6 10

39. S. Bazzaz Bonabi, J. Kahani Khabushan, R. Kahani and A. Honarbakhsh Raouf, Fabrication of Metallic Composite Foam Using Ceramic Porous Spheres Light Expanded Clay Aggregate via Casting Process, Mater. Des., 2014, 64, p 310-315. https://doi.org/10.1016/J. MATDES.2014.07.061

40. A. Szlancsik, D. Kincses and I.N. Orbulov, Mechanical Properties of AlSi10MnMg Matrix Syntactic Foams Filled with Lightweight Expanded Clay Particles, IOP Conf. Ser. Mater. Sci. Eng., 2020, 903, 012045. https://doi.org/10.1088/1757-899X/903/1/012045

41. H. Puga, V.H. Carneiro, C. Jesus, J. Pereira and V. Lopes, Influence of Particle Diameter in Mechanical Performance of Al Expanded Clay Syntactic Foams, Compos. Struct., 2018, 184, p 698-703. https://doi. org/10.1016/J.COMPSTRUCT.2017.10.040

42. A. Szlancsik, B. Katona, A. Kemény and D. Károly, On the Filler Materials of Metal Matrix Syntactic Foams, Mater. (Basel), 2019, 12(12), p 2023. https://doi.org/10.3390/ma12122023
43. C. Kádár, K. Máthis, F. Chmelík, M. Knapek, and I.N. Orbulov, “The Deformation of Expanded Clay Syntactic Foams During Compression Characterized by Acoustic Emission BT - Proceedings of the 11th International Conference on Porous Metals and Metallic Foams (MetFoam 2019)," N. Dukhan, Ed., (Cham), Springer International Publishing, 2020, p 107-114

44. N. Movahedi and E. Linul, Mechanical Properties of Light Expanded Clay Aggregated (LECA) Filled Tubes, Mater. Lett., 2018, 217, p 194197. https://doi.org/10.1016/J.MATLET.2018.01.078

45. A. Kemény, B. Leveles, D.B. Kincses and D. Károly, Manufacturing and Investigation of In-Situ and Ex-Situ Produced Aluminum Matrix Foam-Filled Tubes, Adv. Eng. Mater., 2021 https://doi.org/10.1002/ade m.202100365

46. A. Kemény, B. Leveles and D. Károly, Functional Aluminium Matrix Syntactic Foams Filled with Lightweight Expanded Clay Aggregate Particles, Mater. Today Proc., 2021 https://doi.org/10.1016/j.matpr.20 20.12.164

47. "ISO13314:2011 Mechanical Testing of Metals - Ductility Testing Compression Test for Porous and Cellular Metals," 2011

Publisher's Note Springer Nature remains neutral with regard to jurisdictional claims in published maps and institutional affiliations. 